Article

\title{
Functional Characterization and in Silico Analysis of Phytoene Synthase Family Genes Responsible for Carotenoid Biosynthesis in Watermelon (Citrullus lanatus L.)
}

\author{
Chuan Wu ${ }^{1,2, \dagger}{ }^{+}$Lei Sun ${ }^{1,2,+}$, Yuanzuo Lv ${ }^{1,2}$, Haonan Cui ${ }^{1,2}$, Xuezheng Wang ${ }^{1,2}$, Peng Gao ${ }^{1,2, *}$ \\ and Feishi Luan ${ }^{1,2}$ \\ 1 Key Laboratory of Biology and Genetic Improvement of Horticulture Crops (Northeast Region), Ministry of \\ Agriculture and Rural Affairs, Northeast Agricultural University, Harbin 150030, China; \\ wuchuan8859@126.com (C.W.); sunlei_xjx@163.com (L.S.); 17703650666@163.com (Y.L.); \\ cuihaonan2008@163.com (H.C.); wangxuezheng@neau.edu.cn (X.W.); luanfeishi@neau.edu.cn (F.L.) \\ 2 College of Horticulture and Landscape Architecture, Northeast Agricultural University, \\ Harbin 150030, China \\ * Correspondence: gaopeng1982@neau.edu.cn; Tel.: +86-451-5519-1261 \\ + These authors contributed equally to this work.
}

Received: 25 June 2020; Accepted: 22 July 2020; Published: 26 July 2020

\begin{abstract}
Carotenoids are the main pigments in watermelon (Citrullus lanatus L.) fruit and contribute to its aesthetic and nutritional value. Phytoene synthase (PSY) is reported to be the first rate-limiting enzyme in carotenogenesis and controls the carotenoid flux. This study aimed to identify PSY genes responsible for carotenoid biosynthesis in the red-fleshed watermelon cultivar LSW-177. The PSY gene members ClPSY1, ClPSY2 and ClPSY3 were characterized and their catalytic activities were displayed in the heterologous complementation assay. The transcript levels of CIPSY genes at the different developmental stages of LSW-177 fruit and the promoter sequence of ClPSY1 were also analyzed. Transcription factors involved in regulating the CIPSY1 expression were scanned with previous RNA-seq data of the different stages during fruit ripening. Results showed that the PSY proteins from watermelon LSW-177 contained the conserved PSY domains and exhibited the ability to condense GGPP into phytoene in E. coli. ClPSY1 is the dominant carotenogenic gene during fruit ripening; and can be induced by light and hormones. Furthermore, Cla013914 and Cla007950 that, respectively encode the transcription factors WD40-like protein and bZIP, likely upregulate ClPSY1 during fruit ripening. In conclusion, $C l P S Y 1$ play a dominant role in carotenoid biosynthesis during watermelon fruit ripening and is regulated by complex light and hormone-responsive networks.
\end{abstract}

Keywords: watermelon; carotenoid; phytoene synthase; promoter; transcription factor

\section{Introduction}

The watermelon is an important fruit crop with cultivars that differ in flesh pigmentation due to varying composition and levels of carotenoids [1]. The major carotenoid in the red-fleshed cultivars is lycopene, whereas $\beta$-carotene is the predominant carotenoid in cultivars with yellow flesh [1]. Carotenoids are a large group of natural and lipid-soluble pigments present in photosynthetic organisms some non-photosynthetic organisms, including plants, algae, cyanobacteria and some bacteria [2]. More than 1100 natural carotenoids had been identified so far, of which most are $\mathrm{C}_{40}$ compounds (http://carotenoiddb.jp) [3]. Carotenoids capture light during photosynthesis and also protect plants from photodamage [4,5]. They are also precursors of vitamin A [6], phytohormones $[7,8]$ 
and various flavor and aroma-inducing compounds [9]. In addition, carotenoids and their metabolites can reduce the risk of cancers and improve nutritional quality of horticultural crops [10,11].

The biosynthetic pathways of carotenoids have been studied in many species, including Arabidopsis [12], tomato [13] and citrus fruits [14], etc. Phytoene synthase (PSY), the first rate-limited enzyme of the pathway, condenses GGPP into phytoene and controls the carotenoid flux $[15,16]$. The number of PSY gene families varies across species due to duplication events. While Arabidopsis contains only one copy of the PSY gene [15], two PSY genes have been reported in carrot [17] and three paralogs have been identified in tomato [18-20], cassava [21] and members of the grass family (such as rice [22], maize, [23], etc.). Furthermore, six PSY gene family members have been described in Malus $\times$ domestica and four genes have been amplified [24]. A new MdPSY5 has reported with highly expression in leaves and during fruit ripening of $M$. domestica cv. Fuji' [25]. It was also reported that six members of the PSY gene family were expressed and encoded functional proteins in Brassica napus L. [26]. The presence of multiple PSY genes is indicative of distinct localization (photosynthetic versus non-photosynthetic tissues), as well as developmental stage and environmental response-specific functions [27]. In melon for example, CmPSY2 is the predominant transcript in roots, whereas CMPSY1 is abundant in all other tissues [28]. In addition, tomato SIPSY1 promotes carotenoid accumulation in the fruit while SIPSY 2 mainly functions in the green tissues and SIPSY 3 in roots [18-20]. Similarly, in maize, ZmPSY1 has a dominant role in endosperm carotenogenesis and ZmPSY2 is upregulated by light and associated with photosynthesis [29].

Carotenoid biosynthesis is regulated by phytohormones and environmental factors [30]. The light-responsive bHLH transcription factor PIF1 represses the Arabidopsis PSY gene by binding directly to a G-box motif in its PSY1 promoter [31]. Chromatin immunoprecipitation assays indicated that tomato PIF1a specifically binds to the PBE box of the PSY1 promoter to repress its expression and eventually inhibits carotenoid biosynthesis [32]. Ethylene-responsive factors such as ERFs and RAP2.2 on the other hand transcriptionally activate PSY and increase carotenoid accumulation in Arabidopsis leaves [33]. Recent studies have identified MADS-box transcription factors such as TAGL1 [34], RIN [35] and FUL11 [36] in tomato, which markedly increase carotenoid synthesis and accumulation during fruit ripening by directly or indirectly activating SIPSY1. Other MADS-box proteins like SIMADS1 [37] and SlFYEL [38] are known to repress SIPSY1, while SlCMB1 shows a positive regulatory effect during fruit ripening [39]. The NAC family of TFs also participates in carotenogenesis and affects the transcription of PSY gene. SINAC4 transcriptionally activates SIPSY1 [40] while SINAC1 has the opposite effect [41]. In citrus fruits, CsMADS6 can bind to the promoters of CsPSY and CsPDS and increase their expression levels [14]. RAP2.2 and CubHLH1 are carotenoid metabolism-related TFs that have been isolated from Satsuma mandarin [33,42]. In addition, the abundance and stability of the PSY proteins are also regulated post-transcriptionally. The ORANGE (Or) protein enhances PSY protein stability and increases the enzymatically active form in the plastids of Arabidopsis [43] and sweet potato [44]. On the other hand, the Clp protease physically interacts with PSY protein to enhance its degradation [45]. Both regulators maintain the homeostasis of plastid PSY protein to assure optimal abundance for carotenoid biosynthesis.

Previous studies show that the CILCYB gene controls the flesh color of watermelon [46,47], and the abundance of $C l L C Y B$ correlates negatively with lycopene accumulation [48]. However, given the role of PSY in carotenoid flux, we systematically characterized the functions and comparative gene expression patterns of the duplicated PSY genes in watermelon. We also analyzed the promoter sequences and cis-regulatory structures of CIPSY1 and identified putative transcription factors involved in fruit ripening. 


\section{Materials and Methods}

\subsection{Plant Material and Lycopene Measurement}

The lycopene-rich red fleshed watermelon (Citrullus lanatus L.) cultivars LSW-177 and W1-1 were grown in the greenhouse of Northeast Agricultural University $\left(44^{\circ} 04^{\prime} \mathrm{N}, 125^{\circ} 42^{\prime} \mathrm{E}\right)$, Haerbin, China. The plants were placed under field management using standard horticultural procedures [49]. Samples were scooped from the center of three intact watermelon fruits at five different ripening stages $\left(10,18,26,34\right.$ and $42 \mathrm{DAP}$ or days after pollination) and stored at $-80^{\circ} \mathrm{C}$ until further analysis. The lycopene content was estimated in $3 \mathrm{~g}$ flesh per sample as previously described [48]. Three technical replicates were tested per sample.

\subsection{Isolation of PSY cDNA Sequences and Corresponding Genomic Sequences}

Total RNA was extracted using the RNAprep pure plant kit (Tiangen Biotech, Beijing, China) according to the manufacturer's instructions and $1 \mu \mathrm{g}$ RNA was reverse transcribed to first-strand cDNA using the RevertAid ${ }^{\mathrm{TM}}$-MuLV Kit (MBI, Vilnius, Lithuania) and an oligo dT primer. The open reading frames (ORFs) of watermelon PSY (CIPSY) gene were amplified using primers (Table S1) synthesized according to the sequence available in the Cucurbit genomics database (CuGenDB) (http://cucurbitgenomics.org/). The amplified PCR products were cloned into the pMD19-T Easy vector (TaKaRa, Kyoto, Japan) and transformed into Escherichia coli strain DH5 $\alpha$. The genomic DNA of watermelon samples was extracted using the PlantGen DNA Kit (CWBiotech, Beijing, China) and the promoter and coding regions of ClPSY1 gene were amplified and sequenced.

\subsection{Protein Sequence Analysis}

The signal peptide and transmembrane regions of ClPSY proteins were predicted using CBS prediction servers and the putative conserved domains were analyzed with the help of NCBI conserved domains. The resulting amino acid sequences were aligned using Clustal X v.2.0 [50] and a phylogenetic tree was constructed using MEGA 7.0 by neighbor-joining method and 1000 bootstrap replications [51]. The genomic and coding sequences of ClPSYs from watermelon and other species were compared using TBtools JRE1.6 [52]. The conserved motifs for all PSY protein sequences were detected by multiple expectation maximization for motif elicitation (MEME v.5.1.1) online tools (http://meme-suite.org/tools/ meme).

\subsection{Real-Time PCR Analysis}

Primers specific for ClPSYs exons were designed using the Primer 5.0 software to avoid genomic amplification (Table S1). First, strand cDNA was synthesized using random primers and RT-PCR was performed using SYBR green master mix (TOYOBO, Osaka, Japan) in the iQ5 Gradient Real Time PCR system (Bio-Rad, Berkeley, CA, USA) following the manufacturers' protocols. The reaction conditions were as follows: initial denaturation at $95^{\circ} \mathrm{C}$ for $5 \mathrm{~min}$, followed by 40 cycles of $95^{\circ} \mathrm{C}$ for $15 \mathrm{~s}$ and $60^{\circ} \mathrm{C}$ for $30 \mathrm{~s}$. Relative gene expression was calculated using comparative $C_{T}$ method [53], with the watermelon ClYLS8 gene as the internal control [54]. Three technical replicates were tested for each sample.

\subsection{Plasmids and Functional Complementation}

To test whether the watermelon PSY genes encode functional enzymes, heterologous complementation was performed for the carotenoid biosynthetic genes. The pACCRT-E plasmid carrying the bacterial crtE gene that encodes geranylgeranyldiphosphate synthase (GGPS) was transformed into E. coli [55]. Fragments of ClPSY genes coding sequences were amplified and cloned into the pET28a vector (Novagen, Germany) to generate PETPSY1, pETPSY2 and pETPSY3 constructs. The bacteria carrying pACCRT-E plasmid was co-transformed with the respective CIPSY 
constructs or empty pET28a vector (negative control); (E) coli harboring the pACCRT-EB vector with phytoene-producing $c r t E$ and $c r t B$ genes was used as the positive control. The suitably transformed E. coli cells were cultured at $37^{\circ} \mathrm{C}$ in Luria-Bertani (LB) liquid medium containing $100 \mu \mathrm{g} \mathrm{mL} \mathrm{m}^{-1}$ ampicillin and $35 \mu \mathrm{g} \mathrm{mL} \mathrm{m}^{-1}$ chloramphenicol till $\mathrm{OD}_{600}$ reached 0.6-0.8. After inducing protein expression with $0.05 \mathrm{mM}$ isopropyl- $\beta$-D-thiogalactopyranoside (IPTG), the cells were cultured at $28^{\circ} \mathrm{C}$ for 2 days in the dark without shaking. The cells were harvested by centrifuging at $5000 \times g$ for $15 \mathrm{~min}$ at $4{ }^{\circ} \mathrm{C}$ and washed twice with sterile distilled water. The pellets were resuspended in $5 \mathrm{~mL}$ hexane/acetone (1:1) solution containing 1\% butylated hydroxytoluene (BHT) and sonicated twice on ice. Samples were centrifuged at $4000 \times g$ to remove the lysed cells, and the supernatant was dried under nitrogen. The dried extracts were resuspended in acetone for high-performance liquid chromatography (HPLC) as previously described [56].

\subsection{In Silico Analysis of CIPSY1 Promoter Elements and Related Transcription Factors in Watermelon}

The CIPSY1 promoter sequence was amplified from the genomic DNA of both cultivars using specific primers (Table S1). The nucleotide start site of the CIPSY1 gene was determined using transcription start site (TSS) program of the Softberry software and the cis-regulatory elements were predicted with plantCARE [57] and PLACE [58,59]. The RNA-seq data of watermelon at different ripening stages are available in the NCBI SRA database under the numbers SRX2037189 for cultivar LSW-177 [49] and SUB4001164 for cultivar W1-1 [60]. The expression levels of different transcription factors and CIPSY1 were analyzed at the different stages of fruit ripening.

\section{Results}

\subsection{Characterization of Watermelon PSY Gene and Protein Sequences}

Three watermelon PSY genes were searched in the CuGenDB and BLAST annotation indicated that each mapped to different chromosomes (1, 7 and 2). To determine their role in carotenogenesis, we amplified the CIPSY1, ClPSY2 and CIPSY3 coding sequences from the LSW-177 cultivar. The full-length $1266 \mathrm{bp} C I P S Y 1$ sequence encoded a 421 amino acid protein with a predicted isoelectric point $(p I)$ of 6.86 . The putative protein encoded by ClPSY 2 consisted of 355 amino acids and a $p I$ of 8.46, while the deduced CIPSY3 protein had 388 amino acids and a $p I$ of 8.87. Multiple alignment of the predicted proteins indicated 74.5\% homology between ClPSY1 and ClPSY2 and $67.6 \%$ between CIPSY 3 and ClPSY2. The variable sequences were concentrated in the $\mathrm{N}$-terminal regions and predicted as transit peptides. Both $C l P S Y 2$ and $C l P S Y 3$ contained a shorter $\mathrm{N}$-terminal sequence compared to ClPSY1 (Figure 1). According to the NCBI conserved domains database, watermelon PSYs have six motifs in common (Figure 1 and Figure S1), including the substrate binding pocket, $\mathrm{Mg}^{2+}$ binding site, active site lid residues, catalytic residues and two aspartate-rich sites (DXXXD). The catalytic domains are mainly concentrated between 144-193 aa and 299-348 aa (Figure 1, yellow and pink background). A transmembrane region was also predicted in all three proteins (Figure 1, and Figure S2).

Comparison of the genomic and CDNA sequences revealed that the genomic sequence of ClPSY3 (3180 bp) was longer than that of both CIPSY1 (2886 bp) and ClPSY2 (1902 bp). Furthermore, the coding sequence of CIPSY 1 consisted of 6 exons split by 5 introns similar to that of AtPSY and SIPSYS, compared to 5 exons in both CIPSY2 and CIPSY3 (Figure 2). Analysis of the conserved motifs with MEME identified the same regions as described above. Phylogenetic analysis of ClPSY proteins with that of PSY proteins from other plants showed that the central region was conserved across the species, whereas the N-terminal sequences were diverse on account of the variations in plastid transit peptides. Proteins from watermelon are more closely related to the ones from melon and grouped, respectively. ClPSY1, ClPSY2 and ClPSY 3 were classified into two distinct clades, indicating their different functionality (Figure 2). 


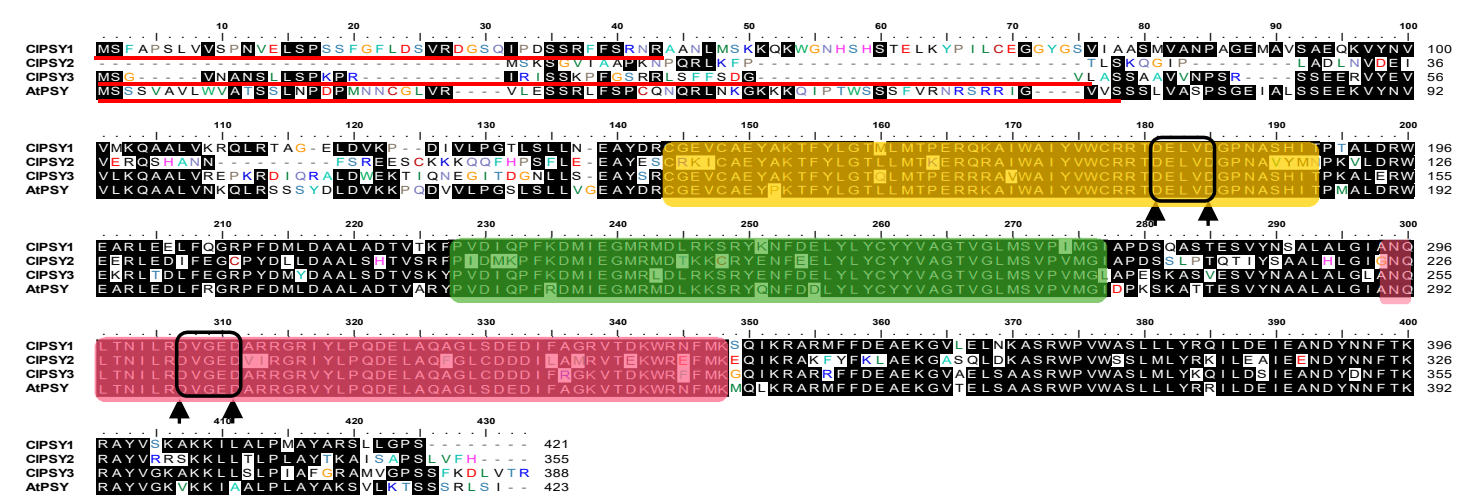

Figure 1. Alignment of watermelon and Arabidopsis phytoene synthase (PSY) proteins. Multiple sequences were aligned using the ClustalX software v.2.0 [50]. The predicted chloroplast cleavage site by chloroP is underlined with red color (http://www.cbs.dtu.dk/services/ChloroP/). Black boxes and arrows indicate the putative active site DXXXD. Catalytic domains are highlighted with yellow and pink and the potential transmembrane region with green (http://www.cbs.dtu.dk/services/TMHMM/).

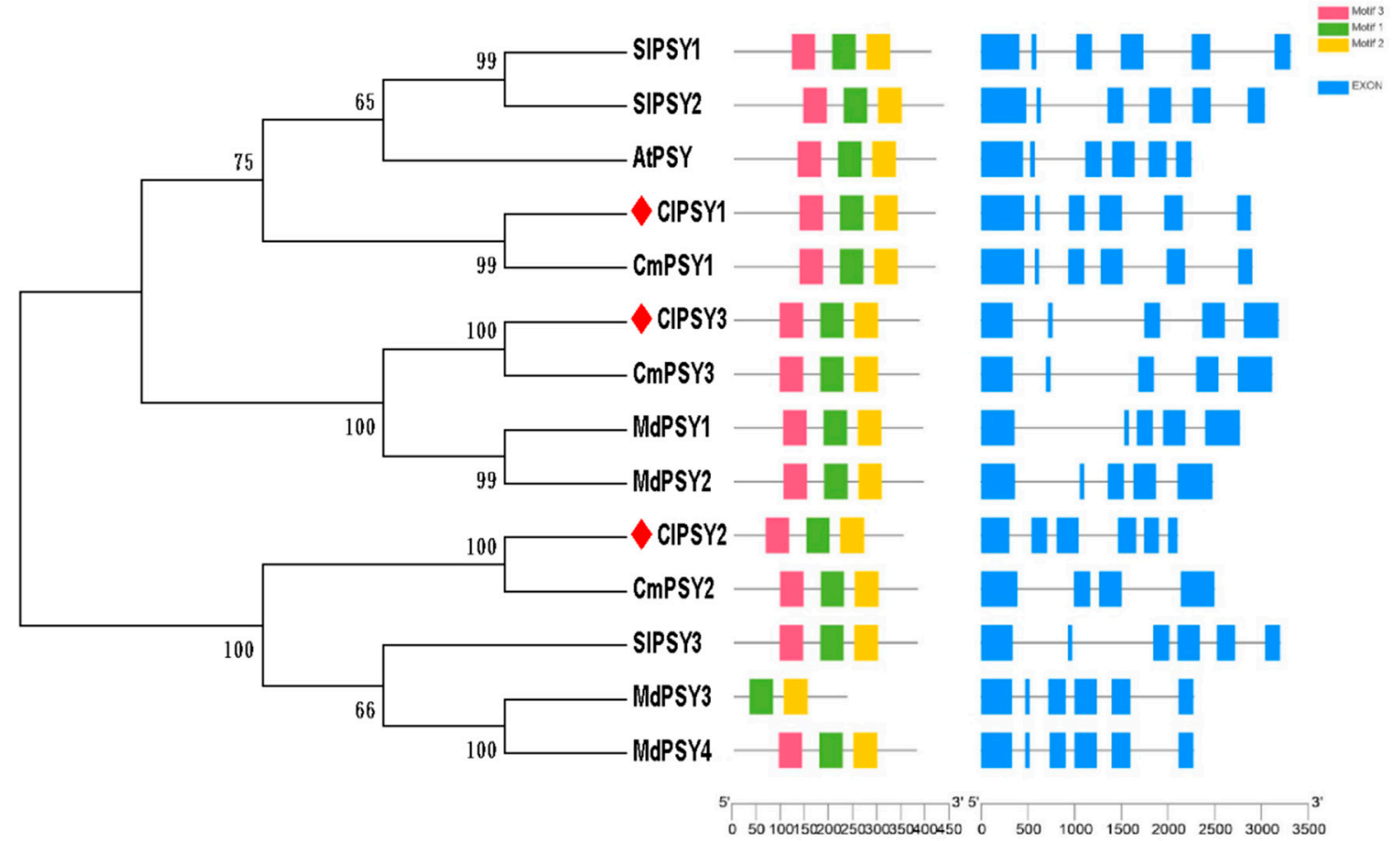

Figure 2. Gene structures of watermelon and other plant PSYS and the distribution of conserved motifs. Left panel shows the phylogenetic tree. The tree was constructed using MEGA7 with a bootstrap of 1000 by the neighbor-joining method [51]. The motif distribution is shown in the middle, wherein rectangles of different colors represent conserved motifs. Color coding is the same as in Figure 1. Exon-intron distribution is shown in the right panel, wherein the black line and blue boxes represent introns and exons, respectively. The database accession numbers are: AtPSY1 (AAA32836), SlPSY1 (CAA42969), SlPSY2 (ABU40771), SlPSY3 (Solyc01g005940), MdPSY1 (KT189149), MdPSY2 (KT189150), MdPSY3 (KT189151), MdPSY4 (KT189152), CmPSY1 (MELO3C025102.2.1), CmPSY2 (MELO3C025102.2.1), CmPSY2 (MELO3C016185.2.1).

\subsection{Functional Complementation}

A heterologous complementation assay was performed to evaluate whether watermelon PSY genes encode functional enzymes. Briefly, the coding sequence of CIPSY1, ClPSY2 and CIPSY3 genes were each introduced into GGPP-expressing E. coli that harbored the pACCRT-E plasmid. phytoene-producing bacteria that carried the PACCRT-EB plasmid was used as the positive control. 
Introduction of the CIPSY1, CIPSY2 and CIPSY3 construct in the pACCRT-E cells resulted in a peak with retention time and spectral qualities similar to that of phytoene (Figure 3). These results indicated all the three PSY genes from watermelon encoded functional proteins and were able to catalyze the conversion of GGPP to phytoene in bacteria.

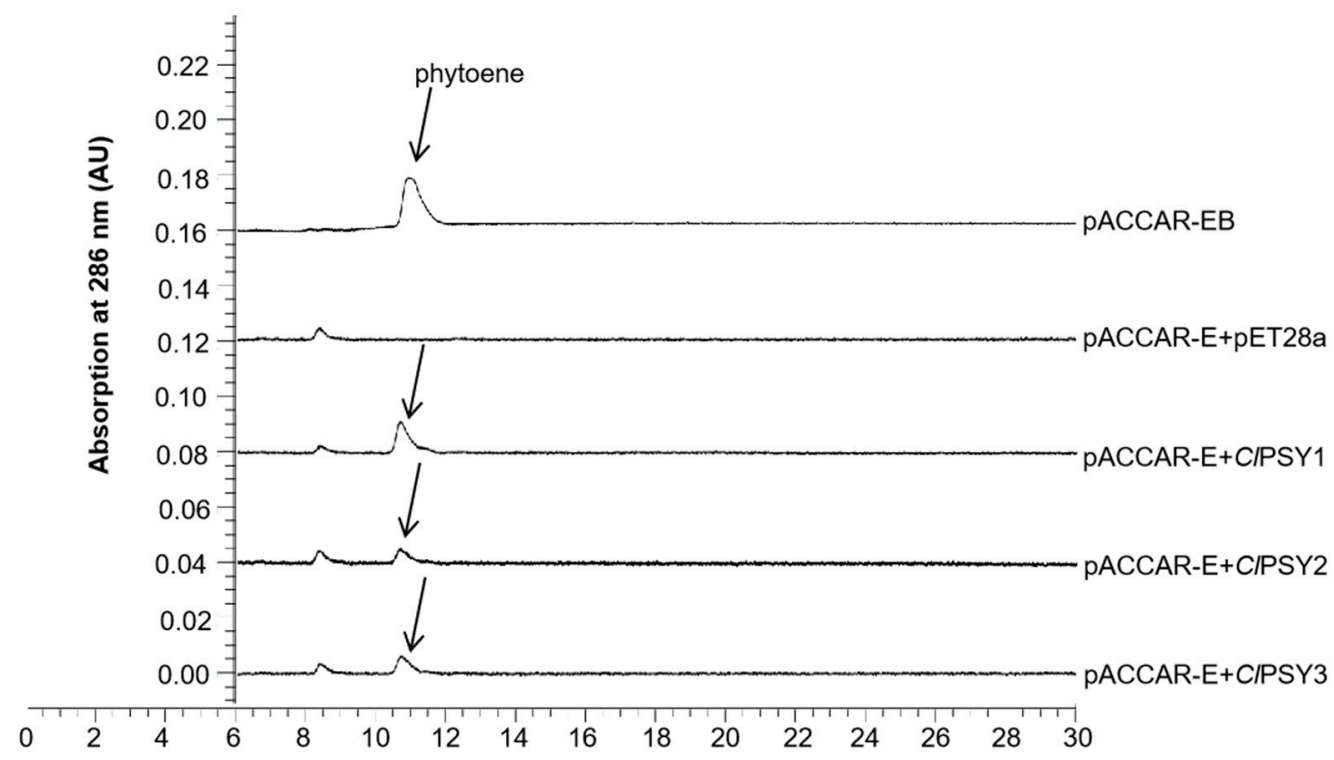

Figure 3. Functional complementation of watermelon PSY proteins in bacteria. E. coli cells harboring the pACCRT-EB vector that contains the $c r t E$ and $c r t B$ genes encoding for phytoene was the positive control. E. coli cells harboring the pACCRT-E vector that contains the $c r t E$ gene encoding for GGPP were transformed with pET28a (empty vector), ClPSY1, ClPSY2 and ClPSY3 constructs. The peak of phytoene (indicated by an arrow) was observed in cells with ClPSY1, ClPSY2 and ClPSY 3 constructs.

\subsection{Carotenoid Synthesis and Accumulation in Watermelon Fruit}

To further determine the role of ClPSY proteins in watermelon carotenogenesis during the ripening period, we measured the lycopene content in the LSW-177 fruit at the different stages. The flesh color of LSW-177 gradually deepened from white to red by 26 DAP due to accumulation of lycopene, which peaked at 42 DAP and corresponded to the deepest red color (Figure 4A). We next detected the transcript levels of CIPSY1, CIPSY2 and CIPSY3 in the fruit flesh at different stages of ripening. CIPSY3 did not alter significantly during ripening, indicating that it does not regulate watermelon fruit maturation. While both CIPSY1 and CIPSY2 had similar transcript profiles till 18 DAP, the CIPSY1 levels were 3.3-fold higher than that of CIPSY2 at 26 DAP and peaked at 42 DAP, which was consistent with the pattern of lycopene accumulation (Figure 4B). Based on these results and previous reports detailing lack of correlation between the CIPSY2 levels and lycopene content in watermelon of different flesh color [61], we hypothesize that CIPSY1 has a dominant role in the carotenoid biosynthetic pathway during watermelon fruit ripening. 

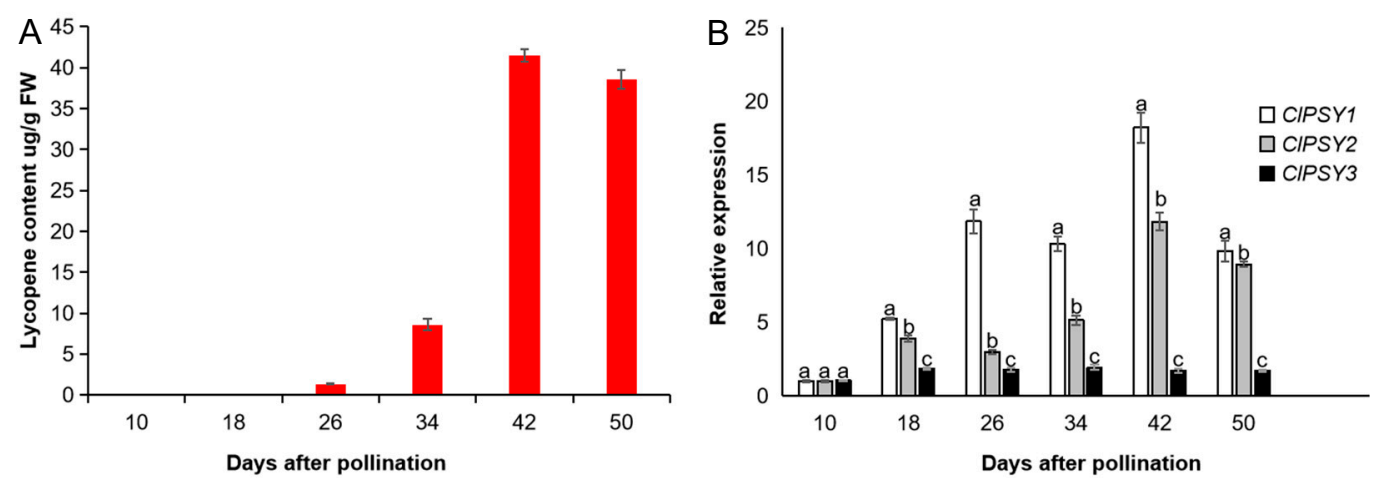

Figure 4. Lycopene content and CIPSY gene expression levels in watermelon fruits at different development stages. (A) Lycopene concentration in watermelon fruits harvested at different time points (days after pollination); (B) relative expression of CIPSY genes at the same time points. Error bars indicate standard errors from three biologic replicates. Different letters indicate significant differences in expression patterns for ClPSY genes $(p<0.05)$.

\subsection{Cis-Regulatory Structures of CIPSY1 Promoter}

The regulatory motifs of most plant genes lie within $2000 \mathrm{bp}$ upstream of the start codon $[62,63]$. To identify the cis-regulatory elements of CIPSY1 and compare the motifs in different watermelon cultivars, we amplified their CIPSY1 genomic sequences $2000 \mathrm{bp}$ upstream of the ATG codon. The reference sequence of red-flesh watermelon 97103 was obtained from Cucurbit genomics database (http://cucurbitgenomics.org/). The predicted TSS was located at about $500 \mathrm{bp}$ upstream from ATG. Putative cis-regulatory elements in the CIPSY1 gene promoter were searched using plantCARE and PLACE programs. Most of the motifs were light-related, including Box 4, G-Box, GT1-motif, chs-CMA1a, AE-box, TCT-motif and Sp1 (Figure 5 and Table S2). Furthermore, hormone-related elements such as ABA-responsive motif ABRE and MeJA-responsive TGACG-motif were also identified in the CIPSY1 gene promoter in all three cultivars. The presence of the ARE motif in the CIPSY1 gene of the three cultivars indicated that is likely induced by anaerobic conditions. Interestingly, the promoter sequence of CIPSY1 from W1-1 and 97103 harbored one G-box motif compared to two in LSW-177. The ATCTA motif, which is recognized by the transcription factor RAP2.2, was only found in the ClPSY1 promoter in LSW-177 and not in W1-1 and 97103.
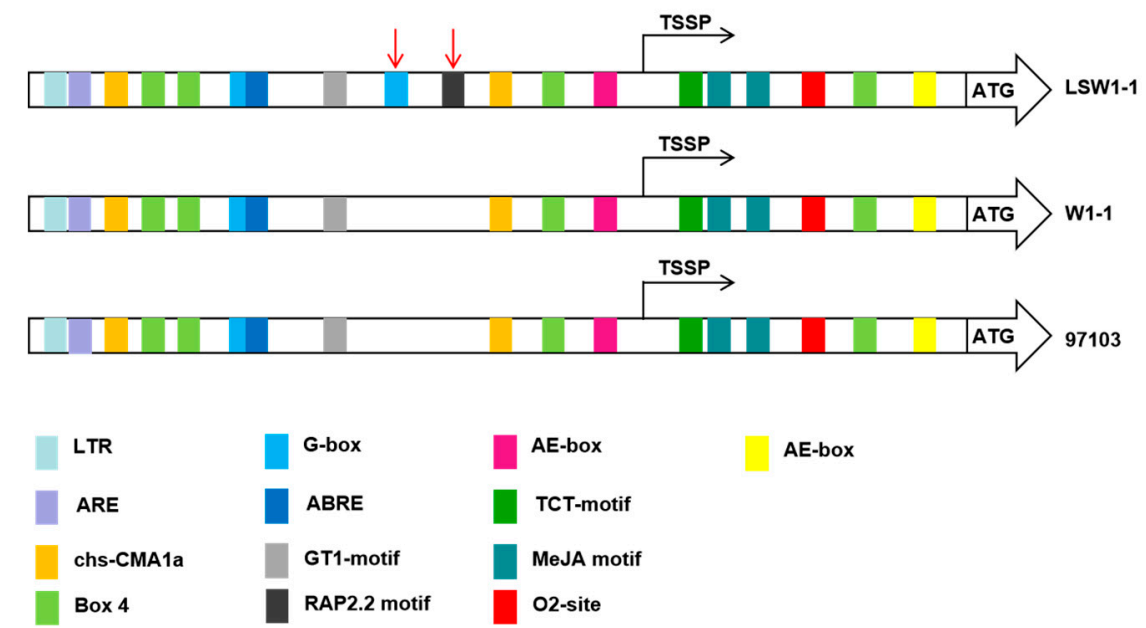

AE-box

Figure 5. Promoter and 5' untranslated regions of CIPSY1 gene from red-flesh watermelon LSW-177, W1-1 and 97103 cultivars. Putative cis-regulatory motifs were identified with plantCARE [57] and PLACE [58,59]. Motifs associated with light and hormonal response are highlighted in different colors. Motif positions are relative and not drawn to scale. Red arrows indicate differences between cultivars. 


\subsection{WD40-Like and bZIP Regulate CIPSY1 Gene Expression during Watermelon Fruit Ripening}

We previously annotated and classified genes that are differentially expressed during watermelon fruit ripening [49]. To further identify transcription factors (TF) that potentially bind to the CIPSY1 promoter and regulate its expression during ripening, we analyzed the RNA-seq data from the different stages of the LSW-177 (10, 18, 26, 34 and 42 DAP) and W1-1 (WA, WB, WC, WD and WE) cultivars. Both transcriptomic and subsequent qPCR analysis indicated that CIPSY1 transcript levels increased rapidly in the first three stages, suggesting that the upstream TFs likely exert their effects in the initial stages of fruit maturation. We then screened for the differentially expressed TFs in these stages based on $p$-value $<0.05, q$ value $<0.05$ and fold change $>1$. Twenty-two TFs were upregulated in the LSW-177 cultivar, including AP2, bHLH, bZIP, MYB, WD40-like and WRKY (Figure 6A and Table S3). In the W1-1 fruits, 50 TFs were upregulated (Figure 6B and Table S4). The Cla013914 and Cla007950 genes, respectively encoding the WD40-like and bZIP TFs were upregulated in both cultivars, indicating that they likely increase CIPSY1 expression levels during fruit ripening.
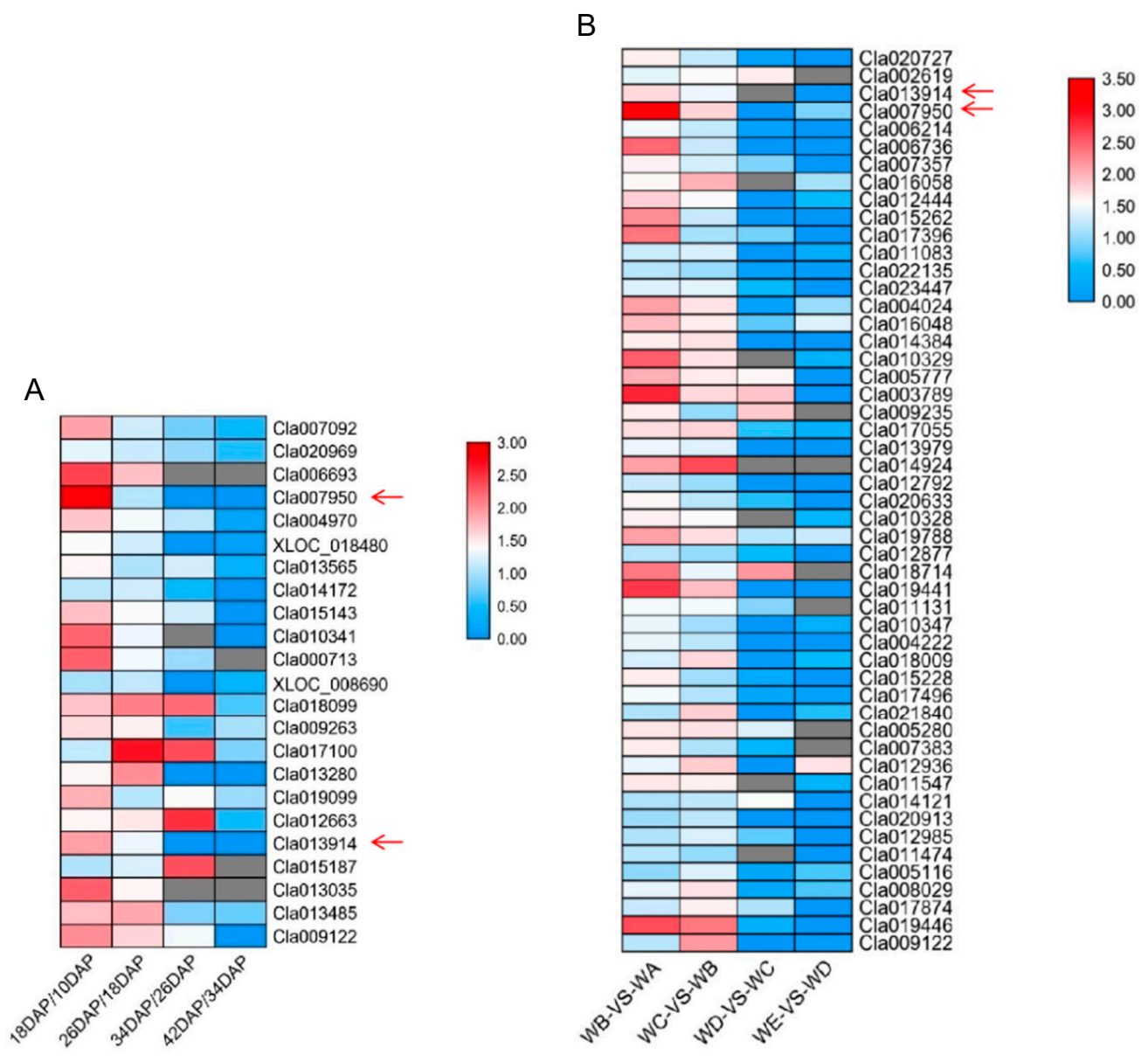

Figure 6. Expression patterns of upregulated transcription factors (TFs) and ClPSY1 gene (Cla009122) at different developmental stages of the LSW-177 and W1-1 cultivars. (A) Expression patterns of 22 upregulated TFs from 10 DAP to 42 DAP in LSW-177; (B) expression patterns of 50 upregulated TFs from 8 DAP to 40 DAP in W1-1. Red and blue boxes indicate differential increase ratio. Red arrows indicate similarity between the cultivars.

\section{Discussion}

The content and composition of carotenoids in the fleshy part of watermelon are highly important traits for breeding new varieties since they contribute to the appearance and nutritional value $[64,65]$. Many transcriptome and QTL genetic linkage experiments had been performed to reveal the genes 
responsible for carotenoid biosynthesis in watermelon fruit ripening $[46,49,65,66]$. Phytoene synthase (PSY) has been confirmed to catalyzes the first committed step of carotenogenesis and therefore controls the carotenoid flux through the pathway in many species $[67,68]$. The aim of this study was to analyze the functionality of ClPSY proteins in order to determine which one was responsible for the carotenoid biosynthesis in the watermelon fruit. In this study, we cloned and identified three PSY-encoding genes from the red-flesh LSW-177 cultivar and designated them as CIPSY1, CIPSY2 and ClPSY3.

The PSY isozymes showed extensive homology in their amino acid sequences with the exception of the N-terminal region. The high diversity in the potential transit peptide at the $\mathrm{N}$-terminal of ClPSYs possibly affect their localization in photosynthetic versus non-photosynthetic tissues, which is also previously observed in Brassica napus and apple PSY proteins [24-26]. In silico analysis further showed the presence of the active aspartate-rich motifs DELVD and DVGED, squalene/PSY signature one and two in each ClPSY protein at the same positions as in AtPSY [15], indicating that these motifs are highly conserved across different species and may origin from the same ancestor $[24,69,70]$. In addition, the watermelon PSY proteins were phylogenetically closer to that of other species than among themselves. For instance, CIPSY1 is organized into six exons similar to that of its homolog in melon (CmPSY1), while the five exon-four intron structure of CIPSY2 and CIPSY3 is comparable to that of MdPSY3/4 and MdPSY1/2 in apples [24]. Furthermore, the structure of ClPSY2 is more divergent with CmPSY2 gene. Taken together, the nonconserved intron/exon structure suggest duplication events and functional diversity.

Complementation assay confirmed that all ClPSY proteins can condense GGPP into phytoene in bacteria. However, they exhibited distinctive expression profiles at the different stages of fruit ripening. The CIPSY 1 transcripts showed a rapid surge in the initial stages of ripening in LSW-177 cultivars, which corresponded to maximum lycopene accumulation, and both showed a subsequent decline in the fully ripened fruit. Guo et al. [66] reported a similar pattern of ClPSY1 expression in the red-flesh 97103 watermelon cultivar. In contrast, its paralog CmPSY1 is predominantly expressed in the ripe melon fruit [28]. Wang et al. [61] analyzed CIPSY2 transcripts in six watermelon cultivars with distinct fruit pigmentation and found that the expression profile of ClPSY2 was not consistent with lycopene accumulation. The red-fleshed MSW28 cultivar had the highest lycopene content, while CIPSY2 displayed lower levels. Finally, ClPSY 3 expression levels did not alter significantly across the different development stages. Taken together, the CIPSY1 gene plays the dominant role in carotenogenesis during watermelon fruit ripening.

Various light- and hormone-responsive elements were identified in the CIPSY1 gene promoter regions from different watermelon cultivars, indicating complex regulatory mechanisms. Chs-CMA1a, Box 4, GT1-motif, AE-box and Sp1 motifs were the common light-responsive elements across LSW-177, W1-1 and 97103 cultivars. In Arabidopsis, PIF1 represses AtPSY transcription by directly binding to a G-box element in its promoter [31]. MabZIP4 directly binds to the BanAAT promoter in banana, while MabZIP5 binds to the promoters of MaMT1, MaACY1, MaAGT1 and BanAAT via the G-box motif, implicating diverse functional roles of MabZIPs during fruit ripening [71]. Fruit growth and ripening are also controlled by multiple phytohormones. For instance, ABA regulates fruit ripening in the watermelon 97103, W1-1 and Pi186490 cultivar [60,72]. We identified ABA and MeJA-responsive elements in the ClPSY1 promoter of LSW-177, W1-1 and 97103 cultivars, suggesting that multiple factors involved in hormone synthesis and signaling regulate ClPSY1 expression during fruit ripening. The ABA-responsive element (ABRE) ACGTG is the major cis-element for ABA-responsive gene expression and TFs containing basic-domain leucine zipper (bZIP) bind to the ABRE sequence in Arabidopsis [73,74]. Furthermore, the MeJA-responsive motif TGACG is a binding site for bZIP that is involved in the MeJA signal transduction pathway [75]. We hypothesize that bZIP regulates CIPSY1 expression via these motifs during watermelon fruit ripening. In addition, an RAP2.2 motif that is recognized by the ethylene response factors (ERF) RAP2.2 were only detected in LSW-177, indicating the distinct regulatory mechanisms between the different cultivars. 
Further screening of the transcriptome data of LSW-177 and W1-1 revealed the TFs Cla013914 and Cla007950 as potential upstream activators of CIPSY1. Cla013914 encodes an unknown protein containing the WD40/YVTN repeat-like-containing domain (IPR015943). The WD40 TF typically contains 4-16 tandem repeat WD motifs that form a scaffold to regulate the assembly and binding of multiple protein complexes involved in plant growth and development [76,77]. A total of 54 putative WD40 genes were differentially expressed between the red-fleshed and white-fleshed peach fruits at five developmental stages [78]. In blueberries, high MYB-bHLH-WD40 expression correlated positively with anthocyanin accumulation and color development [79]. Similar expression patterns have also been detected in the Lycium fruit [80]. Cla007950 encodes a protein of the bZIP family that shows high homology with AtbZIP42. As one of the largest TF families in plants, the bZIP family controls multiple biologic processes, including development, plant growth, fruit ripening and stress responses. Based on these findings, it is highly likely that Cla013914 and Cla007950 activate CIPSY1 in watermelon fruits and promote carotenoid biosynthesis.

\section{Conclusions}

This work presents the structural and functional characterization of phytoene synthase proteins in red-fleshed watermelon LSW-177. Taken together, higher expression levels of ClPSY1 and the ability to generate phytoene in a heterologous system, suggest that CIPSY1 play a dominant role in the carotenoid biosynthesis of watermelon during fruit ripening. This provides a target for watermelon fruit-color breeding. We also analyzed the promoter sequences of CIPSY1 and selected Cla013914 and Cla007950 as the candidate genes that may positively regulate CIPSY1 expression in watermelon during fruit ripening. This study also provide important cues to unveil the underlying mechanisms of carotenoid biosynthesis in watermelon fruit.

Supplementary Materials: The following are available online at http://www.mdpi.com/2073-4395/10/8/1077/s1, Table S1: PCR primers used in the research; Table S2: Putative cis-regulatory elements related to specific function present in CIPSY1 promoter from red-fleshed watermelon cultivars LSW-177, W1-1 and 97103; Table S3: Excel file containing the upregulated transcription factors in LSW-177 at five developmental stages; Table S4: Excel file containing the upregulated transcription factors in W1-1 at five developmental stages; Figure S1: The motifs of watermelon PSY1 protein analyzed using NCBI conserved domains; Figure S2: The transmembrane sequence of watermelon CIPSY1 protein as predicted with CBS prediction servers.

Author Contributions: Conceptualization, C.W. and F.L.; formal analysis, C.W. and L.S.; funding acquisition, P.G. and F.L.; methodology, C.W. and L.S.; project administration, P.G.; resources, X.W. and F.L.; software, Y.L. and H.C.; supervision, F.L.; writing-Original draft, C.W. and L.S.; writing-review \& editing, P.G. and F.L. All authors have read and agreed to the published version of the manuscript.

Funding: This research was funded by the National Key Research and Development Program (2018YFD0100703), the National Nature Science Foundation of China (31601775 and 31572144) and the China Agriculture Research System (CARS-25).

Acknowledgments: The plasmids pACCRT-E and pACCRT-EB were kindly gifted by Misawa.

Conflicts of Interest: The authors declare no conflicts of interest.

\section{References}

1. Perkins-Veazie, P.; Collins, J.K.; Davis, A.R.; Roberts, W. Carotenoid Content of 50 Watermelon Cultivars. J. Agric. Food Chem. 2006, 54, 2593-2597. [CrossRef]

2. Botella-Pavía, P.; Rodríguez-Concepción, M. Carotenoid biotechnology in plants for nutritionally improved foods. Physiol. Plant 2006, 126, 369-381. [CrossRef]

3. Yabuzaki, J. Carotenoids Database: Structures, chemical fingerprints and distribution among organisms. Database 2017, 2017, bax004. [CrossRef]

4. Frank, H.A.; Cogdell, R.J. Carotenoids in photosynthesis. Photochem. Photobiol. 1996, 63, 257-264. [CrossRef]

5. Niyogi, K.K. Photoprotection revisited: Genetic and molecular approaches. Annu. Rev. Plant Physiol. Plant Mol. Biol. 1999, 50, 333-359. [CrossRef] 
6. Clagett-Dame, M.; Knutson, D. Vitamin A in reproduction and development. Nutrients 2011, 3, $385-428$. [CrossRef]

7. Cutler, S.R.; Rodriguez, P.L.; Finkelstein, R.R.; Abrams, S.R. Abscisic acid: Emergence of a core signaling network. Annu. Rev. Plant Biol. 2010, 61, 651-679. [CrossRef] [PubMed]

8. Hou, X.; Rivers, J.; León, P.; McQuinn, R.P.; Pogson, B.J. Synthesis and function of apocarotenoid signals in plants. Trends Plant Sci. 2016, 21, 792-803. [CrossRef] [PubMed]

9. Loreto, F.; Pollastri, S.; Fineschi, S.; Velikova, V. Volatile isoprenoids and their importance for protection against environmental constraints in the Mediterranean area. Env. Exp. Bot. 2014, 103, 99-106. [CrossRef]

10. Fiedor, J.; Burda, K. Potential role of carotenoids as antioxidants in human health and disease. Nutrients 2014, 6, 466-488. [CrossRef] [PubMed]

11. Yuan, H.; Zhang, J.; Nageswaran, D.; Li, L. Carotenoid metabolism and regulation in horticultural crops. Hortic. Res. 2015, 2, 15036. [CrossRef] [PubMed]

12. Ruiz-Sola, M.A.; Rodríguez-Concepción, M. Carotenoid biosynthesis in Arabidopsis: A colorful pathway. Arabidopsis Book 2012, 10, e0158. [CrossRef] [PubMed]

13. Enfissi, E.M.A.; Nogueira, M.; Bramley, P.M.; Fraser, P.D. The regulation of carotenoid formation in tomato fruit. Plant J. 2017, 89, 774-788. [CrossRef] [PubMed]

14. Lu, S.; Zhang, Y.; Zhu, K.; Yang, W.; Ye, J.; Chai, L.; Xu, Q.; Deng, X. The citrus transcription factor CsMADS6 modulates carotenoid metabolism by directly regulating carotenogenic genes. J. Plant Physiol. 2018, 176, 2657-2676. [CrossRef] [PubMed]

15. Rodriguez-Villalon, A.; Gas, E.; Rodriguez-Concepcion, M. Phytoene synthase activity controls the biosynthesis of carotenoids and the supply of their metabolic precursors in dark-grown Arabidopsis seedling. Plant J. 2009, 60, 424-435. [CrossRef] [PubMed]

16. Welsch, R.; Beyer, P.; Hugueney, P.; Kleinig, H.; Lintig, V.J. Regulation and activation of phytoene synthase, a key enzyme in carotenoid biosynthesis, during photomorphogenesis. Planta 2000, 211, 846-854. [CrossRef]

17. Clotault, J.; Peltier, D.; Berruyer, R.; Thomas, M.; Briard, M.; Geoffriau, E. Expression of carotenoid biosynthesis genes during carrot root development. J. Exp. Bot. 2008, 59, 3563-3573. [CrossRef]

18. Fantini, E.; Falcone, G.; Frusciante, S.; Giliberto, L.; Giuliano, G. Dissection of Tomato Lycopene Biosynthesis through Virus-Induced Gene Silencing. Plant Physiol. 2013, 163, 986-998. [CrossRef]

19. Wang, H.; Ou, C.; Zhuang, F.; Ma, Z. The dual role of phytoene syntehase genes in carotenogenesis in carrot roots and leaves. Mol. Breed. 2014, 34, 2065-2079. [CrossRef]

20. Giorio, G.; Stigliani, A.L.; D'Ambrosio, C. Phytoene synthase genes in tomato (Solanum lycopersicum L.) -New data on the structures, the deduced amino acid sequences and the expression patterns. FEBS J. 2008, 275, 527-535. [CrossRef]

21. Arango, J.; Wust, F.; Beyer, P.; Welsch, R. Characterization of phytoene synthases from cassava and their involvement in abiotic stress-mediated responses. Planta 2010, 232, 1251-1262. [CrossRef] [PubMed]

22. Chaudhary, N.; Nijhawan, A.; Khurana, J.P.; Khurana, P. Carotenoid Biosynthesis Genes in Rice: Structural Analysis, Genome-Wide Expression Profiling and Phylogenetic Analysis. Mol. Genet. Genomics. 2010, 283, 13-33. [CrossRef] [PubMed]

23. Dibari, B.; Murat, F.; Chosson, A.; Gautier, V.; Poncet, C.; Lecomte, P.; Mercier, I.; Bergès, H.; Pont, C.; Blanco, A.; et al. Deciphering the genomic structure, function and evolution of carotenogenesis related phytoene synthases in grasses. BMC Genomics 2012, 13, 221. [CrossRef] [PubMed]

24. Ampomah-Dwamena, C.; Driedonks, N.; Lewis, D.; Shumskaya, M.; Chen, X.; Wurtzel, E.; Espley, R.; Allan, A. The Phytoene synthase gene family of apple (Malus $\mathrm{x}$ domestica) and its role in controlling fruit carotenoid content. BMC Plant Biol. 2015, 15, 185. [CrossRef]

25. Cerda, A.; Moreno, J.C.; Acosta, D.; Godoy, F.; Cáceres, J.C.; Cabrera, R.; Stange, C. Functional characterization and in silico modelling of MdPSY2 variants and MdPSY5 phytoene synthases from Malus domestica. J. Plant Physiol. 2020, 249, 153166. [CrossRef] [PubMed]

26. López-Emparán, A.; Quezada-Martinez, D.; Zúñiga-Bustos, M.; Cifuentes, V.; Iñiguez-Luy, F.; Federico, M.L. Functional Analysis of the Brassica napus L. Phytoene Synthase (PSY) Gene Family. PLoS ONE 2014, 9, e114878. [CrossRef]

27. Shumskaya, M.; Wurtzel, E. The carotenoid biosynthetic pathway: Thinking in all dimensions. Plant Sci. 2013, 208, 58-63. [CrossRef] 
28. Qin, X.Q.; Coku, A.; Inoue, K.; Tian, L. Expression, subcellular localization, and cis-regulatory structure of duplicated phytoene synthase genes in melon (Cucumis melo L.). Planta 2011, 234, 737-748. [CrossRef]

29. Li, F.; Vallabhaneni, R.; Yu, J.; Rocheford, T.; Wurtzel, E.T. The maize phytoene synthase gene family: Overlapping roles for carotenogenesis in endosperm, photomorphogenesis, and thermal stress tolerance. Plant Physiol. 2008, 147, 1334-1346. [CrossRef]

30. Dumas, Y.; Dadomo, M.; Lucca, G.D.; Grolier, P. Effects of environmental factors and agricultural techniques on antioxidant content of tomatoes. J. Sci. Food Agric. 2003, 83, 369-382. [CrossRef]

31. Toledo-Ortiz, G.; Huq, E.; Rodríguez-Concepción, M. Direct regulation of phytoene synthase gene expression and carotenoid biosynthesis by phytochrome-interacting factors. Proc. Natl. Acad. Sci. USA 2010, 107, 11626. [CrossRef] [PubMed]

32. Llorente, B.; D'Andrea, L.; Ruiz-Sola, M.A.; Botterweg, E.; Pulido, P.; Andilla, J.; Loza-Alvarez, P.; Rodriguez-Concepcion, M. Tomato fruit carotenoid biosynthesis is adjusted to actual ripening progression by a light-dependent mechanism. Plant J. 2016, 85, 107-119. [CrossRef] [PubMed]

33. Welsch, R.; Maass, D.; Voegel, T.; DellaPenna, D.; Beyer, P. Transcription factor RAP2.2 and its interacting partner SINAT2: Stable elements in the carotenogenesis of Arabidopsis leaves. Plant Physiol. 2007, 145, 1073-1085. [CrossRef] [PubMed]

34. Vrebalov, J.; Pan, I.; Arroyo, A.J.; Mcquinn, R.; Chung, M.; Poole, M.; Rose, J.; Seymour, G.; Grandillo, S.; Giovannoni, J.; et al. Fleshy fruit expansion and ripening are regulated by the tomato SHATTERPROOF gene TAGL1. Plant Cell. 2009, 21, 3041-3062. [CrossRef] [PubMed]

35. Qin, G.; Wang, Y.; Cao, B.; Wang, W.; Tian, S. Unraveling the regulatory network of the MADS box transcription factor RIN in fruit ripening. Plant J. 2012, 70, 243-255. [CrossRef] [PubMed]

36. Bemer, M.; Karlova, R.; Ballester, A.; Tikunov, Y.; Bovy, A.; Wolters-Arts, M.; de Barros Rossetto, P.; Angenent, G.C.; de Maagd, R.A. The tomato FRUITFULL homologs $\mathrm{TDR}_{4} / \mathrm{FUL}_{1}$ and $\mathrm{MBP}_{7} / \mathrm{FUL}_{2}$ regulate ethylene-independent aspects of fruit ripening. Plant Cell. 2012, 24, 4437-4451. [CrossRef] [PubMed]

37. Dong, T.; Hu, Z.; Deng, L.; Wang, Y.; Zhu, M.; Zhang, J.; Chen, G. A tomato MADS-box transcription factor, SIMADS1, acts as a negative regulator of fruit ripening. J. Plant Physiol. 2013, 163, 1026-1036. [CrossRef] [PubMed]

38. Xie, Q.; Hu, Z.; Zhu, Z.; Dong, T.; Zhao, Z.; Cui, B.; Chen, G. Overexpression of a novel MADS-box gene SIFYFL delays senescence, fruit ripening and abscission in tomato. Sci. Rep. 2014, 4, 4367. [CrossRef]

39. Zhang, J.; Hu, Z.; Yao, Q.; Guo, X.; Nguyen, V.; Li, F.; Chen, G. A tomato MADS-box protein, SlCMB1, regulates ethylene biosynthesis and carotenoid accumulation during fruit ripening. Sci. Rep. 2018, 8, 3413. [CrossRef]

40. Zhu, M.; Chen, G.; Zhou, S.; Tu, Y.; Wang, Y.; Dong, T.; Hu, Z. A new tomato NAC (NAM ATAF1/2/CUC2) transcription factor, SINAC4, functions as a positive regulator of fruit ripening and carotenoid accumulation. Plant Cell Physiol. 2014, 55, 119-135. [CrossRef]

41. Meng, C.; Yang, D.; Ma, X.; Zhao, W.; Liang, X.; Ma, N.; Meng, Q. Suppression of tomato SINAC1 transcription factor delays fruit ripening. J. Plant Physiol. 2016, 193, 88-96. [CrossRef] [PubMed]

42. Endo, T.; Fujii, H.; Sugiyama, A.; Nakano, M.; Nkajima, N.; Ikoma, Y.; Omura, M.; Shimada, T. Overexpression

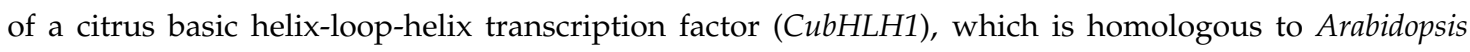
activation-tagged bri1 suppressor 1 interacting factor genes, modulates carotenoid metabolism in transgenic tomato. Plant Sci. 2016, 243, 35-48. [CrossRef]

43. Zhou, X.; Welsch, R.; Yang, Y.; Álvarez, D.; Riediger, M.; Yuan, H.; Fish, T.; Liu, J.; Thannhauser, T.; Li, L. Arabidopsis OR proteins are the major posttranscriptional regulators of phytoene synthase in controlling carotenoid biosynthesis. Proc. Natl. Acad. Sci. USA 2015, 112, 3558-3563. [CrossRef] [PubMed]

44. Park, S.; Kim, H.; Jung, Y.; Kim, S.; Ji, C.Y.; Wang, Z.; Jeong, J.; Lee, H.; Kwak, S. Orange Protein Has a Role in Phytoene Synthase Stabilization in Sweetpotato. Sci. Rep. 2016, 6, 33563. [CrossRef]

45. Welsch, R.; Zhou, X.; Yuan, H.; Álvarez, D.; Sun, T.; Schlossarek, D.; Yang, Y.; Shen, G.; Zhang, H.; Rodriguez-Concepcion, M.; et al. Clp Protease and OR Directly Control the Proteostasis of Phytoene Synthase, the Crucial Enzyme for Carotenoid Biosynthesis in Arabidopsis. Mol. Plant 2017, 11, 149-162. [CrossRef]

46. Liu, S.; Gao, P.; Wang, X.; Davis, A.; Baloch, M.; Luan, F. Mapping of quantitative trait loci for lycopene content and fruit traits in Citrullus lanatus. Euphytica 2015, 202, 411-426. [CrossRef] 
47. Wang, C.; Qiao, A.; Fang, X.; Sun, L.; Gao, P.; Davis, A.; Liu, L.; Luan, F. Fine Mapping of Lycopene Content and Flesh Color Related Gene and Development of Molecular Marker-Assisted Selection for Flesh Color in Watermelon (Citrullus lanatus). Front. Plant Sci. 2019, 10, 1240. [CrossRef]

48. Zhang, J.; Sun, H.; Guo, S.; Ren, Y.; Li, M.; Wang, J.; Zhang, H.; Gong, G.; Xu, Y. Decreased Protein Abundance of Lycopene $\beta$-Cyclase Contributes to Red Flesh in Domesticated Watermelon. Plant Physiol. 2020, 22, 01409. [CrossRef]

49. Zhu, Q.; Gao, P.; Liu, S.; Zhu, Z.; Amanullah, S.; Davis, A.; Luan, F. Comparative transcriptome analysis of two contrasting watermelon genotypes during, fruit development and ripening. BMC Genomics 2017, 18, 3. [CrossRef]

50. Thompson, J.; Gibson, T.; Plewniak, F.; Jeanmougin, F.; Higgins, D. The CLUSTAL_X windows interface: Flexible strategies for multiple sequence alignment aided by quality analysis tools. Nucleic Acids Res. 1997, 25, 4876-4882. [CrossRef]

51. Kumar, S.; Stecher, G.; Tamura, K. MEGA7: Molecular evolutionary genetics analysis version 7.0 for biggerdatasets. Mol. Biol. Evol. 2016, 33, 1870-1874. [CrossRef] [PubMed]

52. Chen, C.; Xia, R.; Chen, H.; He, Y. TBtools, a Toolkit for Biologists integrating various HTS-data handling tools with a user-friendly interface. bioRxiv 2018. [CrossRef]

53. Schmittgen, T.; Livak, K. Analyzing Real-Time PCR Data by the Comparative C(T) Method. Nat. Protoc. 2008, 3, 1101-1108. [CrossRef]

54. Kong, Q.; Yuan, J.; Gao, L.; Zhao, S.; Jiang, W.; Huang, Y.; Bie, Z. Identification of Suitable Reference Genes for Gene Expression Normalization in qRT-PCR Analysis in Watermelon. PLoS ONE 2014, 9, e90612. [CrossRef] [PubMed]

55. Misawa, N.; Nakagawa, M.; Kobayashi, K.; Yamano, S.; Izawa, Y.; Nakamura, K.; Harashima, K. Elucidation of the Erwinia uredovora carotenoid biosynthetic pathway by functional analysis of gene products expression in Escherichia coli. J. Bacteriol. 1990, 172, 6704-6712. [CrossRef]

56. Castillo, R.; Fernandez, J.A.; Gomez-Gomez, L. Implications of carotenoid biosynthetic genes in apocarotenoid formation during the stigma development of Crocus sativus and its closer relatives. Plant Physiol. 2005, 139, 674-689. [CrossRef] [PubMed]

57. Lescot, M.; Dehais, P.; Thijs, G.; Marchal, K.; Moreau, Y.; Van de Peer, Y.; Rouzé, P.; Rombauts, S. PlantCARE, a database of plant cis-acting regulatory elements and a portal to tools for in silico analysis of promoter sequences. Nucleic Acids Res. 2002, 30, 325-327. [CrossRef]

58. Higo, K.; Ugawa, Y.; Iwamoto, M.; Higo, H. PLACE: A database of plant cis-acting regulatory DNA elements. Nucleic Acids Res. 1998, 26, 358-359. [CrossRef]

59. Shahmuradov, I.; Gammerman, A.; Hancock, J.; Bramley, P.; Solovyev, V. PlantProm: A database of plant promoter sequences. Nucleic Acids Res. 2003, 31, 114-117. [CrossRef]

60. Sun, L.; Zhang, Y.S.; Cui, H.N.; Zhang, L.P.; Sha, T.Y.; Wang, C.N.; Fan, C.; Luan, F.S.; Wang, X.Z. Linkage Mapping and Comparative Transcriptome Analysis of Firmness in Watermelon (Citrullus lanatus). Front. Plant Sci. 2020, 11, 831. [CrossRef]

61. Wang, N.; Liu, S.; Gao, P.; Luan, F.; Davis, A. Developmental Changes in Gene Expression Drive Accumulation of Lycopene and $\beta$-Carotene in Watermelon. J. Am. Soc. Hortic. Sci. 2016, 141, 434-443. [CrossRef]

62. Dwivedi, K.K.; Roche, D.; Carman, J.G. Expression in Arabidopsis of a nucellus-specific promoter from watermelon (Citrullus lanatus). Plant Sci. 2010, 179, 549-552. [CrossRef] [PubMed]

63. Conforte, A.J.; Guimarães-Dias, F.; Neves-Borges, A.C.; Bencke-Malato, M.; Felix-Whipps, D.; Alves-Ferreira, M. Isolation and characterization of a promoter responsive to salt, osmotic and dehydration stresses in soybean. Genet. Mol. Biol. 2017, 40, 226-237. [CrossRef] [PubMed]

64. Tadmor, Y.; King, S.; Levi, A.; Davis, A.; Meir, A.; Wasserman, B.; Hirschberg, J.; Lewinsohn, E. Comparative fruit colouration in watermelon and tomato. Food Res. Int. 2005, 38, 837-841. [CrossRef]

65. Grassi, S.; Piro, G.; Lee, J.; Zheng, Y.; Fei, Z.J.; Dalessandro, G.; Giovannoni, J.J.; Lenucci, M.S. Comparative genomics reveals candidate carotenoid pathway regulators of ripening watermelon fruit. BMC Genomics 2013, 14, 781. [CrossRef] [PubMed]

66. Guo, S.; Sun, H.; Zhang, H.; Liu, J.; Ren, Y.; Gong, G.; Jiao, C.; Zheng, Y.; Yang, W.; Fei, Z.; et al. Comparative Transcriptome Analysis of Cultivated and Wild Watermelon during Fruit Development. PLoS ONE 2015, 10, e0130267. [CrossRef] 
67. Gallagher, C.E.; Matthews, P.D.; Li, F.; Wurtzel, E.T. Gene duplication in the carotenoid biosynthetic pathway preceded evolution of the grasses. Plant Physiol. 2004, 135, 1776-1783. [CrossRef]

68. Shewmaker, C.K.; Sheehy, J.A.; Daley, M.; Colburn, S.; Ke, D.Y. Seed specific overexpression of phytoene synthase:increase in carotenoids and other metabolic effects. Plant J. 1999, 20, 401-412. [CrossRef]

69. Fu, X.; Feng, C.; Wang, C.; Yin, X.; Lu, P.; Grierson, D.; Xu, C.; Chen, K. Involvement of multiple phytoene synthase genes in tissue- and cultivar-specific accumulation of arotenoids in loquat. J. Exp. Bot. 2014, 65, 4679-4689. [CrossRef]

70. Alquezar, B.; Zacarias, L.; Rodrigo, M.J. Molecular and functional characterization of a novel chromoplast-specific lycopene $\beta$-cyclase from Citrus and its relation to lycopene accumulation. J. Exp. Bot. 2009, 60, 1783-1797. [CrossRef]

71. Guo, Y.; Zhang, Y.; Shan, W.; Cai, Y.; Liang, S.; Chen, J.; Lu, W.; Kuang, J. Identification of Two Transcriptional Activators MabZIP4/5 in Controlling Aroma Biosynthetic Genes during Banana Ripening. J. Agric. Food Chem. 2018, 66, 6142-6150. [CrossRef] [PubMed]

72. Wang, Y.; Guo, S.; Tian, S.; Zhang, J.; Ren, Y.; Sun, H.; Gong, G.; Xu, Y. Abscisic Acid Pathway Involved in the Regulation of Watermelon Fruit Ripening and Quality Trait Evolution. PLoS ONE 2017, 12, e0179944. [CrossRef] [PubMed]

73. Choi, H.; Hong, J.; Ha, J.; Kang, J.; Kim, S.Y. ABFs, a family of ABA-responsive element binding factors. J. Biol. Chem. 2000, 275, 1723-1730. [CrossRef] [PubMed]

74. Uno, Y.; Furihata, T.; Abe, H.; Yoshida, R.; Shinozaki, K.; Yamaguchi-Shinozaki, K. Arabidopsis basic leucine zipper transcription factors involved in an abscisic acid-dependent signal transduction pathway under drought and high-salinity conditions. Proc. Natl. Acad. Sci. USA. 2000, 97, 11632-11637. [CrossRef] [PubMed]

75. Rouster, J.; Leah, R.; Mundy, J.; Cameron-Mills, V. Identification of a Methyl Jasmonate-Responsive Region in the Promoter of a Lipoxygenase 1 Gene Expressed in Barley Grain. Plant J. 1997, 11, 513-523. [CrossRef] [PubMed]

76. Smith, T.; Gaitatzes, C.; Saxena, K.; Neer, E. The WD repeat: A common architecture for diverse functions. Trends Biochem. 1999, 24, 181-185. [CrossRef]

77. Jain, B.; Pandey, S. WD40 Repeat Proteins: Signalling Scaffold with Diverse Functions. Protein J. 2018, 37, 391-406. [CrossRef]

78. Feng, R.; Zhang, C.; Ma, R.; Cai, Z.; Yu, M. Identification and characterization of WD40 superfamily genes in peach. Genes 2019, 710, 291-306. [CrossRef]

79. Zhao, M.; Li, J.; Zhu, L.; Chang, P.; Li, L.; Zhang, L. Identification and Characterization of MYB-bHLH-WD40 Regulatory Complex Members Controlling Anthocyanidin Biosynthesis in Blueberry Fruits Development. Genes 2019, 10, 496. [CrossRef]

80. Li, G.; Zhao, J.; Qin, B.; Yin, Y.; An, W.; Mu, Z.; Cao, Y. ABA Mediates Development-Dependent Anthocyanin Biosynthesis and Fruit Coloration in Lycium Plants. BMC Plant Biol. 2019, 19, 317. [CrossRef] 